\title{
ПРОБЛЕМЫ РЕАЛИЗАЦИИ СОЦИАЛЬНЫХ ПРАВ ИНВАЛИДОВ ПО СЛУХУ И ПО ЗРЕНИЮ В РОССИИ И ВОЗМОЖНЫЕ ПУТИ ИХ РЕШЕНИЯ
}

\section{PROBLEMS OF REALIZATION OF THE SOCIAL RIGHTS OF THE HEARING AND VISION DISABLED IN RUSSIA AND POSSIBLE WAYS TO SOLVE THEM}

T. Matveeva N. Kuznetsova

Summary. Life and health are fundamental human values that should be protected by the state. The social policy of the Russian Federation in relation to people suffering from complete or partial loss of vision or hearing is aimed at providing disabled people with opportunities to realize universally recognized constitutional human and civil rights and freedoms. This policy affects the most common area - healthcare. This article discusses the main problems faced by a person with hearing and vision limitations, as well as ways to resolve the current situation in Russia.

Keywords: visually and audibly disabled; social responsibilities of the Russian Federation; health care system; free medicine; social security.

\author{
Матвеева Тамара Павловна \\ Старший преподаватель, ФКОУ ВО «Владимирский \\ юридический институт ФСИН России» \\ matveeva33@mail.ru \\ Кузнецова Наталья Александровна \\ Старший преподаватель, ФКОУ ВО «Владимирский \\ юридический институт ФСИН России» \\ kuz1503@yandex.ru
}

Аннотация. Жизнь и здоровье - это основополагающие ценности человека, которые должны быть под охранной государства. Социальная политика Российской Федерации по отношению к людям, страдающим полной или частичной потерей зрения или слуха, направлена на обеспечение инвалидам возможностей в реализации общепризнанных конституционных прав и свобод человека и гражданина. Данная политика затрагивает наиболее распространённую сферу — здравоохранение. В данной статье рассмотрены основные проблемы, с которыми сталкивается человек имеющий ограничения по слуху и по зрению, а также пути разрешения сложившейся в России ситуации.

Ключевые слова: инвалиды по зрению и по слуху; социальные обязанности РФ; система здравоохранения; бесплатная медицина; социальное обеспечение.

родиться инвалидом или приобрести ограничение здоровья в течение жизни. В Российской Федерации на данный момент (середина 2021 года) насчитывается 10796766 инвалидов по различным причинам инвалидности. [5]

Причины наступления инвалидности могут быть различны, как и заболевание, которое послужило этому, но все связано с утратой здоровья.

Мы хотим затронуть проблемы лиц, являющихся инвалидами по слуху и по зрению.

В настоящее время, тугоухость является одной из достаточно распространенных заболеваний у людей, уступая при этом другим заболеваниям. Слепота, тоже не уступает потери слуха, но все-таки, число людей, страдающих потерей зрения, в половину меньше, чем людей, страдающих полной или частичной потерей слуха. Согласно статистике в мире 466 миллионов человек страдает от потери слуха, около 39 миллионов страдают полностью потерей зрения, в России по данным 
Минздрава насчитывают около 200 тысяч инвалидов по слуху и 218 тысяч людей, ограниченных по зрению $[2,3]$.

С принятием Конституции и внесением в последующем в нее поправок утверждается обязанность государства по социальному обеспечению граждан Российской Федерации. Так в Основном законе страны гарантируется право на охрану здоровья и медицинскую помощь всем без исключения нуждающимся. Помимо этого, в Российской Федерации создаются и реализуются Правительством РФ государственные программы направленные на восстановление и модернизацию системы здравоохранения.

В Конституции РФ также говориться, что медицинские услуги в государственных и муниципальных учреждениях здравоохранения должны осуществляться бесплатно. Но на практике услуги, предоставляемые на основании полиса обязательного медицинского страхования, имеют ограниченный перечень. Поэтому граждане нередко вынуждены обращаться в частные клиники, что является затратным удовольствием для обычного россиянина.

В связи с тем, что инвалиды по слуху или зрению, да и вообще люди имеющие инвалидность в большинстве случаях относятся к категории малообеспеченных, некоторые из них находятся в пределах бедности, то им необходимо предоставлять бесплатные медицинские услуги в особом порядке как льготной категории населения.

Для работы с пациентами, имеющими инвалидность по слуху и зрению, необходима особая техника, особые препараты, что естественно является недешевым удовольствием, которое государственное учреждение в большинстве случаев не может себе позволить. В нашей стране существует распространенное мнение по поводу невысокого качества бесплатной медицины, поэтому уровень обращения такой категории граждан за медицинской помощью ежегодно находится на низком уровне.

Федеральная служба государственной статистики ежегодно приводит опросы среди лиц, обладающих статусом инвалида, о причинах их не обращения в государственные медицинские организации за помощью. [4] Согласно опубликованной Росстатом статистике, самой распространенной причиной является неудовлетворенность медицинской организацией, около $30 \%$ человек, говорят именно об этом. Приходя в больницы, инвалиды часто сталкиваются с неуважением к себе, что врачи обвиняют самого человека в своих проблемах, даже не разобравшись в них. Зачастую из-за про- фессиональной деформации, врачи становятся более грубыми, неаккуратными, и идти к таким специалистам уже не хочется. Также, что касается оборудования или лекарственного обеспечения, очень часто в маленьких городах или в сельской местности, нет необходимой техники, лекарств и медицинских специалистов, поэтому пропадает смысл обращаться за медицинской помощью. Из этого вытекает и вторая причина, что около $20 \%$ людей, не рассчитывают на эффективное лечения.

Bce необходимые технические средства должны предоставляться данной категории инвалидов на льготных условиях. Но очень часто, не всегда получается бесплатно выделять необходимую технику, и единственным вариантом остается получение её на платной основе, этого данные категории граждан позволить себе в большинстве случаев не могут.

Согласно статье 19 Ф3 «Об основах охраны здоровья граждан в РФ» любой гражданин, обратившийся за помощью, имеет право на облегчение своей проблемы доступными средствами и медицинскими препаратами. Из этого вытекает, что предоставление лечебных препаратов входит в обязательную медицинскую помощь. В связи с этим инвалиды по слуху и зрению имеют право на предоставление им необходимых препаратов, причем в некоторых случаях даже на льготных основах. Льготы государство предоставляет, потому что отсутствие лекарств у малообеспеченных нуждающихся граждан, может привести к риску усугубления его физических ограничений и привести к неблагоприятным последствиям для всего организма. Поэтому препараты для инвалидов должны стать доступными, это означает, что они могут быть предоставлены бесплатно или хотя бы со скидкой, и должны быть в том городе или поселении, где живет человек. Поэтому возникает проблема нехватки такого препарата, на той или иной территории, что приводит к повышению цены на жизненно важный препарат для инвалида.

Для получения таких препаратов необходимо получить рецепт от врача, а если нет необходимого специалиста по месту жительства, придется искать такого специалиста, добираться до него, получать рецепт, потом искать этот препарат. Из одной проблемы вытекает другая проблема, неудивительно, что люди выбирают путь к целителям, заговорщицам и сомневаются в современной медицине. Так как это все намного доступнее, но о гарантии качества тут даже и говорить не хочется.

Ещё одной причиной является месторасположение необходимой организации, если не везде можно получить нужную медицинскую помощь, то и не каждый человек с потерей зрения или слуха, может добрать- 
ся до этой медицинской организации. Поэтому около 7\% людей аргументируют свое нежелание обращаться в медицинские организации тем, что они не смогут до неё добраться без посторонней помощи или же им очень тяжело до неё доехать, ведь это также может быть связанно с финансовыми возможностями.

Помимо этого, большая проблема в получении бесплатной помощи лежит на безответственности страховых организаций и незащищенности пациента. Так как люди, имеющие инвалидность, в большинстве случаев, мало социально активны, и их мобильность очень снижена, они не могут сами защищать свои права на предоставления им бесплатных и качественных медицинских услуг.

Многим инвалидам создают стационар на дому, и никто не рассчитывает, что в большинстве случаев им нужна будет помощь в каждодневном уходе, помощь в получении пищи и так далее. Создание стационаров на дому - это очень удобно тем, что больницы остаются, не так перегружены, но все равно это очень затратно. Работа с инвалидами, это достаточно трудоемкая деятельность, которая оказывает психологические и физические нагрузки, отсюда и возникает проблема нежелания работников идти или браться за таких пациентов, а ко всему этому и оплата данной работы не так уж и высока, ведь энергии уходит в разы больше, чем они получают на выходе. [1]

Для решения вышеуказанных проблем, связанных с предоставлением медицинских услуг гражданам являющимися инвалидами по слуху и по зрению, государству в первую очередь необходимо расширить перечень тех услуг, которые могут оказываться по полису обязательного медицинского страхования за счет средств бюджета и страховых компаний ОМС. Также необходимо оснастить государственные и муниципальные медицинские учреждения всеми необходимыми современными технологиями и обеспечить необходимое количество лекарств предназначенных для нуждающихся в этом россиян. Конечно, для реализации этого необходимы большие финансовые затраты, которые бюджет не выдержит. Поэтому, все надо реализовывать узко направленно, и первостепенно обеспечить этой возможностью граждан относящихся к категории инвалидов.

Таким образом, мы выделили основные проблемы, которые показывают нам, что получать медицинские услуги инвалидам по слуху или зрению, не так и просто. Люди не обращаются за помощью из-за того, что в их населенном пункте нет необходимых специалистов, или отсутствуют необходимые технические средства, ведь оснащение больниц достаточно затратное занятие и не всегда из бюджета можно выделить необходимое финансирование. Из-за плохого отношения к пациентам, а в особенности нежелание работать с людьми, имеющими какие-то ограничения, персонал отбивает какое-либо желание обращаться к ним. Из-за сложности данной работы и низкого заработка, врачи сами не горят желание иметь дело с такими пациентами. Из-за отсутствия нужного опыта работы с инвалидами по слуху и зрению, понижается эффективность помощи данным граждан. Предоставление препаратов тоже является большой проблемой, часто из-за нехватки таких лекарств, и завышенной цены.

\section{ЛИТЕРАТУРА}

1. Пузин С.Н., Предоставление медицинской помощи и медикосоциальных услуг инвалидам и лицам пожилого возраста в Российской Федерации. Современные возможности и перспективы / С.Н. Пузин, Л.П. Храпылина, В.В. Кудрявцев, М.3. Каплан, А.Е. Лаптева // Медико-социальная экспертиза и реабилитация, 2016.- - С. 3.

2. Нарушение слуха в цифрах (статистика). // URL: https://sluh.online/statistika. (дата обращения: 12.08.2021).

3. Статистика слепых и инвалидов по зрению в России, СНГ и мире. - URL: https://tiflocentre.ru/stati/kolichestvo-slepyh-i-invalidov-po-zreniju-v-Rossii. php. (дата обращения: 12.08.2021)

4. Причины необращения за медицинской помощью в медорганизации и получение медицинской помощи из других источников инвалидов в возрасте 15 лет и более. Федеральная служба государственной статистики.— URL: http://old.gks.ru/wps/wcm/connect/rosstat_main/rosstat/ru/statistics/ population/disabilities/\#. (дата обращения: 30.01.2021).

5. Федеральная государственная информационная система. https://sfri.ru/

( ) Матвеева Тамара Павловна ( matveeva33@mail.ru ), Кузнецова Наталья Александровна ( kuz1503@yandex.ru ). Журнал «Современная наука: актуальные проблемы теории и практики» 